\title{
Isolation and Characterization of Myosin from Walleye Pollack Surimi
}

\author{
Takao Ojima, Satoshi Yoshikawa, and Kiyoyoshi Nishita \\ Department of Marine Bioresources Chemistry, Faculty of Fisheries, \\ Hokkaido University, Hakodate, Hokkaido 041, Japan
}

(Received January 21, 1997)

\begin{abstract}
Actomyosin was extracted from myofibrils obtained from walleye pollack frozen surimi with $0.5 \mathrm{M}$ $\mathrm{KCl}, 1 \mathrm{M}$ sorbitol, and $1 \mathrm{mM} \mathrm{Mg}$-ATP. Myosin was separated from F-actin by ultracentrifugation in the presence of $\mathrm{MgCl}_{2}$ and ATP. The myosin consisted of heavy chains of $\mathrm{Mr} \mathrm{200,000}$ and light chains of Mr 25,000, 18,000, and 17,000. Ca-ATPase activity of the myosin decreased approximately $20 \%$ per day at $0^{\circ} \mathrm{C}$ in $0.5 \mathrm{M} \mathrm{KCl}(\mathrm{pH} 7.0)$ containing $1 \mathrm{M}$ sorbitol. Ca-ATPase specific activity was approximately 8 times lower but EDTA-ATPase specific activity was several times higher than those of rabbit myo$\sin$ at $0.05-0.5 \mathrm{M} \mathrm{KCl}$, although the respective activities of both myosins showed similar dependences on $\mathrm{KCl}$ and $\mathrm{pH}$. The $\mathrm{Mg}$-ATPase activity of pollack myosin was increased approximately 100 times by the addition of an equal weight of rabbit F-actin and the activity was approximately 5 times higher than that of rabbit myosin. On the other hand, the actomyosin showed a significant increase in $\mathrm{Mg}$-ATPase activity upon incubating at $20-30^{\circ} \mathrm{C}$, probably due to some irreversible conformational changes of myosin. The pollack myosin formed mini-filaments of about $0.5 \mu \mathrm{m}$ length and the filaments tended to aggregate with each other.
\end{abstract}

Key words: walleye pollack, frozen surimi, myosin, ATPase, filament, morphology

Frozen surimi of walleye pollack is one of the most important materials used in the food processing industry especially for "kamaboko" in Japan and some foreign countries because of its high gel forming ability and mass productivity. To understand the relationship between the meat processing method and gel-forming mechanism, many investigations have been carried out using meat paste, myofibrils and myosin B of fish such as walleye pollack, carp, and some others ${ }^{1-6)}$ and warm-blooded vertebrates. ${ }^{7 \rightarrow 9}$ It has been shown that heat-induced gelation, which is closely related to the quality of the meat products, is dependent on the irreversible myosin polymerization in the myofibrils. ${ }^{7-11}$ However, the molecular mechanism of the myosin polymerization is still obscure and detailed investigations are required in rather simple systems. Therefore, it is important to clarify the properties of the myosin from surimi.

Monomeric myosin of walleye pollack was isolated from surimi by Kimura et $a l .{ }^{12)}$ using ammonium sulfate fractionation in the presence of $1 \mathrm{M}$ sodium glutamate to prevent aggregation. However, its biochemical properties have not been investigated sufficiently.

In the present study, we describe the preparation of walleye pollack myosin from frozen surimi and its basic biochemical properties compared with those of rabbit myosin.

\section{Materials and Methods}

Frozen surimi (SA grade) of walleye pollack Theragra chalcogramma was kindly supplied by Nippon Suisan Co., Lid. and stored at $-40^{\circ} \mathrm{C}$ within one year. Rabbit myosin and actin were prepared from the fast skeletal muscle by the methods of Perry ${ }^{13)}$ and Spudich and Watt, ${ }^{14)}$ respectively. Sorbitol was obtained from Towa Kasei Co., Ltd. and other reagents were of biochemical research grade.

ATPase activity was measured at $15^{\circ} \mathrm{C}$ in the presence of $5 \mathrm{mM} \mathrm{CaCl}{ }_{2}$ (Ca-ATPase), $5 \mathrm{~mm}$ EDTA (EDTAATPase), or $2 \mathrm{mM} \mathrm{MgCl}_{2}$ (Mg-ATPase), in $0.05-0.5 \mathrm{M}$ $\mathrm{KCl}, 25 \mathrm{~mm}$ Tris maleate (pH 7.0), $1 \mathrm{~mm} \mathrm{ATP}$, and 0.05 $\mathrm{mg} / \mathrm{m} l$ myosin as follows: the pollack myosin $(0.5 \mathrm{ml})$ was added to the ice-cold reaction mixture $(4 \mathrm{~m} l)$ and preincubated at $15^{\circ} \mathrm{C}$ for $5 \mathrm{~min}$, then $0.5 \mathrm{ml}$ of $10 \mathrm{~mm}$ ATP was added to initiate ATPase reaction. At appropriate intervals $(1-6 \mathrm{~min}), 1 \mathrm{ml}$ of the reaction mixture was pipetted out and added to $2 \mathrm{ml}$ of $15 \%$ trichloroacetic acid to terminate the reaction, then liberated inorganic phosphate was determined by the method of Youngburg and Youngburg. ${ }^{15)}$ Actin-activated Mg-ATPase activity was measured in the presence of $0.01-0.1 \mathrm{mg} / \mathrm{m} / \mathrm{F}$-actin and $50 \mathrm{mM} \mathrm{KCl}$. SDS-PAGE was carried out by the method of Porzio and Pearson. ${ }^{16}$ The protein concentration was determined by the biuret method ${ }^{17}$ using bovine serum albumin Fraction $\mathrm{V}$ as a standard protein.

Walleye pollack myosin was prepared as follows: frozen surimi $(6.5 \mathrm{~g})$ was homogenized with $65 \mathrm{~m} /$ of $1 \mathrm{M}$ sorbitol, $50 \mathrm{mM} \mathrm{KCl}, 20 \mathrm{mM}$ Tris maleate (pH 7.0), and $5 \mathrm{~mm} 2$-mercaptoethanol, in a Waring blender for $15 \mathrm{~s}$; homogenization was repeated four times. The homogenate was then mixed with $65 \mathrm{~m} l$ of the same solution and centrifuged at $10,000 \times g$ for $10 \mathrm{~min}$ to remove the supernatant. The washing was repeated twice more. The resulting precipitates of myofibrils were then suspended with $65 \mathrm{ml}$ of $1 \mathrm{mM}$ sodium bicarbonate and $5 \mathrm{~mm} 2$-mercaptoethanol to remove 
troponin-tropomyosin* from the myofibrils. After gentle stirring for $10 \mathrm{~min}$ at $0^{\circ} \mathrm{C}$, the suspension was centrifuged at $10,000 \times g$ for $10 \mathrm{~min}$ to collect the precipitates. This washing procedure was repeated once more since it was essential to minimize the contamination of tropomyosintroponin, which were hardly removed from the myosin by further purification. Then, the myofibrils were mixed with $65 \mathrm{ml}$ of $0.5 \mathrm{M} \mathrm{KCl}, 1 \mathrm{M}$ sorbitol, $20 \mathrm{mM}$ Tris maleate $(\mathrm{pH}$ 7.0), $1 \mathrm{mM} \mathrm{MgCl}_{2}, 1 \mathrm{mM} \mathrm{ATP}$, and $5 \mathrm{~mm}$ 2-mercaptoethanol to extract actomyosin. After $15 \mathrm{~min}$, the mixture was centrifuged at $10,000 \times g$ for $15 \mathrm{~min}$, and the supernatant obtained was added to $650 \mathrm{~m} l$ of cold distilled water. The precipitated actomyosin was collected by centrifugation at $10,000 \times g$ for $15 \mathrm{~min}$, and dissolved in $1 \mathrm{M}$ sorbitol, $0.5 \mathrm{M} \mathrm{KCl}$, and $20 \mathrm{~mm}$ Tris maleate ( $\mathrm{pH} 7.0$ ). Actomyosin was then dissociated to actin and myosin by the addition of $0.2 \mathrm{M} \mathrm{MgCl}_{2}$ and $5 \mathrm{mM} \mathrm{ATP}$, and actin was removed by ultracentrifugation at $100,000 \times g$ for $1 \mathrm{~h}$. The supernatant was diluted with 10 volumes of cold distilled water containing $5 \mathrm{~mm} 2$-mercaptoethanol, and precipitated myosin was collected by centrifugation at $10,000 \times g$ for $10 \mathrm{~min}$. The myosin was dissolved in and dialyzed against

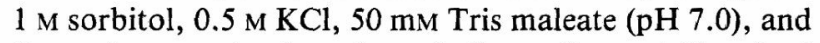
$5 \mathrm{~mm}$ 2-mercaptoethanol, and then ultracentrifuged at $100,000 \times g$ for $1 \mathrm{~h}$ before use. The yield was $100-120 \mathrm{mg}$ myosin from $6.5 \mathrm{~g}$ of surimi.

Myosin filaments were formed as follows: $0.5 \mathrm{ml}$ of myosin solution $(1.0 \mathrm{mg} / \mathrm{ml})$ in $1 \mathrm{M}$ sorbitol, $0.5 \mathrm{M} \mathrm{KCl}, 50$ $\mathrm{mM}$ Tris maleate (pH 7.0), and $5 \mathrm{~mm} 2$-mercaptoethanol was transferred into a test tube of $1.7 \mathrm{~cm}$ diameter. It was then diluted slowly by adding $4 \mathrm{vol}$ of $20 \mathrm{mM}$ Tris maleate (pH 7.0) under continuous stirring with a magnetic stirrer, so as to make the final concentration of $0.2 \mathrm{mg} / \mathrm{m} l$ myosin, $0.2 \mathrm{M}$ sorbitol, $0.1 \mathrm{M} \mathrm{KCl}, 20 \mathrm{~mm}$ Tris maleate $(\mathrm{pH}$ 7.0), and $1 \mathrm{~mm} 2$-mercaptoethanol taking $1.5 \mathrm{~min}$. After incubation at $8^{\circ} \mathrm{C}$ for $5 \mathrm{~min}$, the filaments formed were applied to a grid, negatively stained with $2 \%$ uranyl acetate, and then observed by a Hitachi $\mathrm{H}-7000$ electron microscope at an acceleration voltage of $75 \mathrm{kV}$.

\section{Results and Discussion}

\section{Preparation of Myosin}

Myosin was prepared by the method described in "Materials and Methods"' which is the same method as used for scallop myosin ${ }^{18)}$ except for the use of $1 \mathrm{M}$ sorbitol to prevent protein denaturation.

Judging from SDS-PAGE (Fig. 1), the pollack myosin was contaminated by less than two percent of actin and was practically free from tropomyosin-troponin, and consisted of heavy chain of Mr 200,000, and light chains of $\operatorname{Mr} 25,000,18,000$, and 17,000 similarly to carp and tilapia myosins. ${ }^{19)}$

\section{ATPase Activity of Pollack Myosin}

Changes in Ca-ATPase activity of the pollack myosin were examined during storage in $1 \mathrm{M}$ sorbitol, $0.5 \mathrm{M} \mathrm{KCl}$, $50 \mathrm{~mm}$ Tris maleate (pH 7.0), and $5 \mathrm{~mm}$ 2-mercaptoethanol at $0^{\circ} \mathrm{C}$. As shown in Fig. 2, the activity

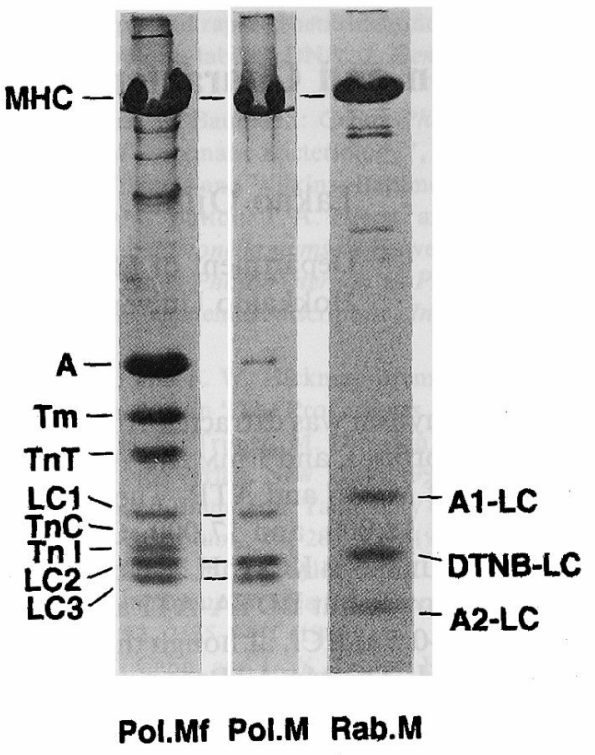

Fig. 1. SDS-polyacrylamide gel electrophoresis of the walleye pollack myosin.

Electrophoresis was carried out by the method of Porzio and Pearson ${ }^{16}$ with $10 \%$ polyacrylamide and $0.1 \%$ SDS. Coomassie Brilliant Blue R-250 was used to stain the gel. Pol. Mf, pollack myofibrils (15 $\mu \mathrm{g})$; Pol. M, pollack myosin ( $5 \mu \mathrm{g})$; Rab. M, rabbit myo$\sin (5 \mu \mathrm{g})$. MHC, myosin heavy chain (Mr 200,000); A, actin (Mr 43,000); Tm, tropomyosin ( $\mathrm{Mr} \mathrm{34,000),} \mathrm{TnT,} \mathrm{troponin-} \mathrm{T}$ (Mr 29,000), LCl, myosin light chain-1 (Mr 25,000); TnC, Troponin-C (Mr 22,000); TnI, Troponin-I (Mr 21,000); LC2, myosin light chain2 (Mr 18,000); LC3, myosin light chain-3 (Mr 17,000); Al-LC, myosin alkali light chain-1 (Mr 26,000); DTNB-LC, myosin DTNB-light chain (Mr 17,500); A2-LC, myosin alkali light chain-2 (Mr 15,500).

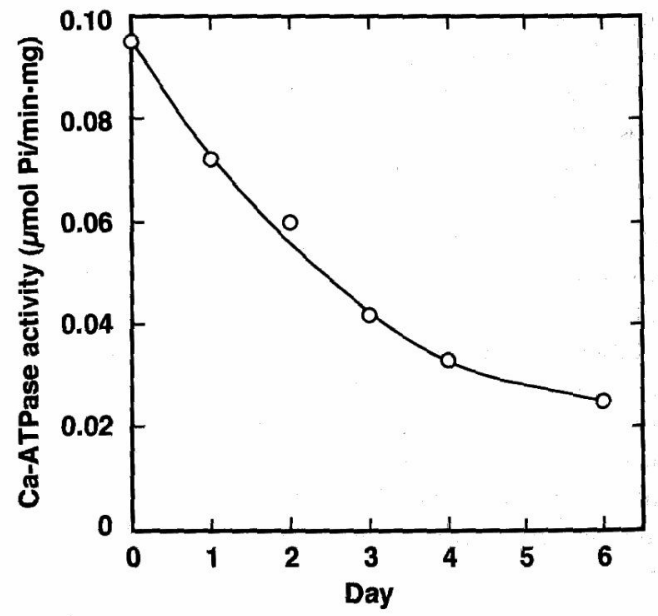

Fig. 2. Decrease in Ca-ATPase activity of the walleye pollack myosin during storage.

The pollack myosin $(10 \mathrm{mg} / \mathrm{m} l)$ was stored at $0^{\circ} \mathrm{C}$ in $1 \mathrm{M}$ sorbitol, $0.5 \mathrm{M} \mathrm{KCl}, 50 \mathrm{mM}$ Tris maleate $(\mathrm{pH} 7.0$ ), and $5 \mathrm{~mm} 2$-mercaptoethanol. The storage time (day) of the myosin is indicated on the abscissa.

\footnotetext{
* According to our preliminary experiments, the proteins of $\mathrm{Mr} 34,000,29,000,22,000$, and 21,000 have been assigned as tropomyosin, troponin- $\mathrm{T}$, troponin-C, and troponin-I, respectively.
} 
decreased about $20 \%$ per day, and its half life was about 2.5 days. Accordingly, we used a myosin preparation as soon as possible, at least within 2 days.

The KCl-dependences of the Ca- and EDTA-ATPase activities of the pollack and rabbit myosins were determined at $15^{\circ} \mathrm{C}$ as shown in Fig. 3. Comparing with rabbit myosin, pollack myosin showed approximately 8 times lower Ca-ATPase activity at $0.05-0.5 \mathrm{M} \mathrm{KCl}$, while both myosins showed the same $\mathrm{KCl}$-dependence. That is, the Ca-ATPase activities of both pollack and rabbit myosins simply decreased with increase in $\mathrm{KCl}$ concentration. On the other hand, the EDTA-ATPase activity of pollack myosin also showed similar KCl-dependence to that of rabbit myo$\sin$, however, it was activated more readily with lower $\mathrm{KCl}$ concentration than that of rabbit myosin below $0.5 \mathrm{M} \mathrm{KCl}$. Furthermore, the activity of pollack myosin decreased at $\mathrm{KCl}$ concentrations higher than $0.5 \mathrm{M}$, probably because of denaturation of the myosin by salt.

The $\mathrm{pH}$-dependences of Ca- and EDTA-ATPase activities of the pollack and rabbit myosins are shown in Fig. 4A and $\mathrm{B}$. The maximal Ca-ATPase activity of the pollack myosin was seen at $\mathrm{pH} 6.4$ and 8.8, and the minimum at around $\mathrm{pH} 7.2-7.6$, while the maximal EDTA-ATPase activity was seen at pH 8.0. The Ca-ATPase activity in the pH range higher than 8.8 and the EDTA-ATPase activity in the $\mathrm{pH}$ range higher than 8.0 decreased unlike the activities of rabbit myosin. The decreases may be partly due to denaturation at alkaline $\mathrm{pH}$.

Figure 5 shows the Mg-ATPase activity of the pollack and rabbit myosins in the presence of various amounts of F-actin. The activity of pollack myosin increased approximately 100 times by the addition of an equal weight of rabbit F-actin, and the specific activity was approximately 5 times higher than that of rabbit myosin at a weight ratio of 1:1 for myosin:F-actin. This strong actin-activation for pollack myosin Mg-ATPase was also observed in myosin prepared from fresh muscle of pollack (data not shown).
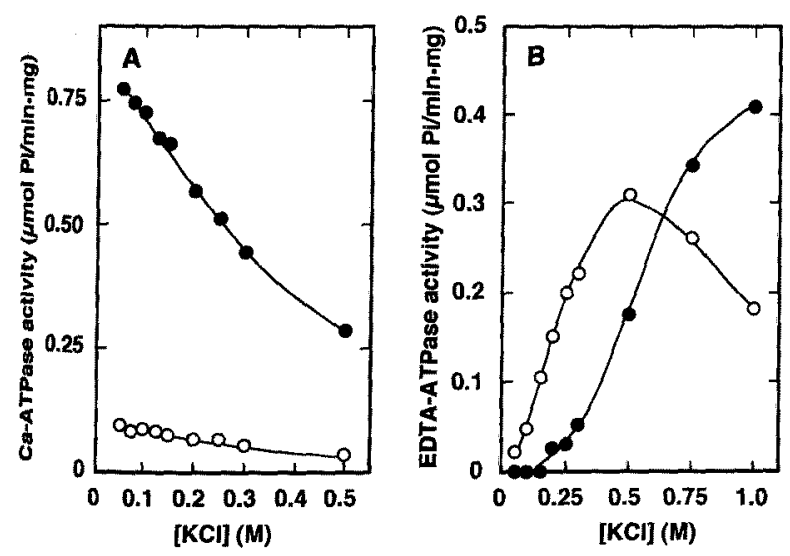

lig. 3. Dependence on $\mathrm{KCl}$ concentration of $\mathrm{Ca}$ - and EDTA-ATPase activities of the walleye pollack and rabbit myosins.

ATPase activity was measured at $15^{\circ} \mathrm{C}$ in a following medium: $\mathrm{A}$, $5 \mathrm{mM} \mathrm{CaCl}, 25 \mathrm{~mm}$ Tris maleate (pH 7.0), $1 \mathrm{mM} \mathrm{ATP}, 0.05 \mathrm{mg} / \mathrm{m} /$ myosin, $0.1 \mathrm{M}$ sorbitol, and various concentrations of $\mathrm{KCl} ; \mathrm{B}, 5 \mathrm{mM}$ EDTA, $25 \mathrm{~mm}$ Tris maleate (pH 7.0), $1 \mathrm{mM}$ ATP, $0.05 \mathrm{mg} / \mathrm{m} / \mathrm{myo}-$ sin, $0.1 \mathrm{M}$ sorbitol, and various concentrations of $\mathrm{KCl}$. 0 , pollack myosin; $\bullet$, rabbit myosin.
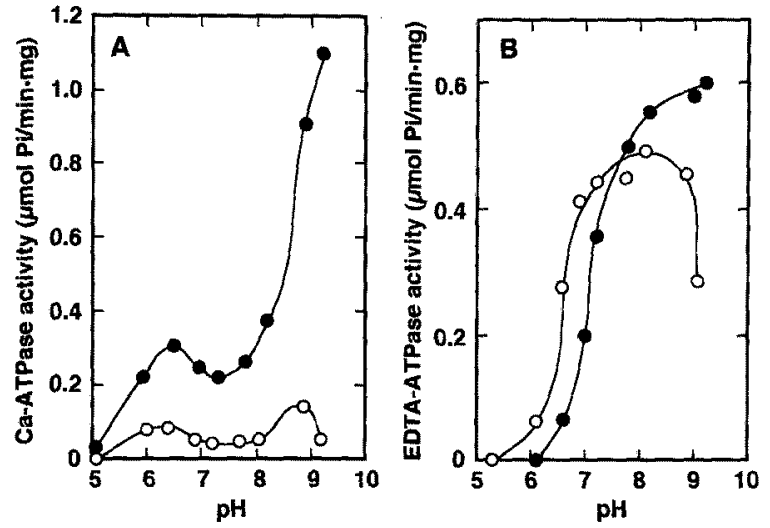

Fig. 4. Dependence on $\mathrm{pH}$ of $\mathrm{Ca}-$ and EDTA-ATPase activities of the walleye pollack and rabbit myosins.

ATPase activity was measured at $15^{\circ} \mathrm{C}$ in the following medium: A, $0.5 \mathrm{M} \mathrm{KCl}, 5 \mathrm{mM} \mathrm{CaCl}, 0.1 \mathrm{M}$ sorbitol, $0.05 \mathrm{mg} / \mathrm{m} / \mathrm{myosin}, 1$ $\mathrm{mM}$ ATP, $50 \mathrm{mM}$ Tris- $\mathrm{HCl}(\mathrm{pH} \mathrm{7-10)}$ or Tris maleate ( $\mathrm{pH} \mathrm{4-7);} \mathrm{B,}$ $0.5 \mathrm{M} \mathrm{KCl}, 5 \mathrm{mM}$ EDTA, $0.1 \mathrm{M}$ sorbitol, $0.05 \mathrm{mg} / \mathrm{m} / \mathrm{myosin}, 1 \mathrm{~mm}$ ATP, $50 \mathrm{~mm}$ Tris-HCl (pH 7-10) or Tris maleate ( $\mathrm{pH} \mathrm{4-7).} \mathrm{The} \mathrm{pH}$ value indicated in the figures was the value of the medium measured immediately after ATPase assay. $O$, pollack myosin; $\bullet$, rabbit myo$\sin$.

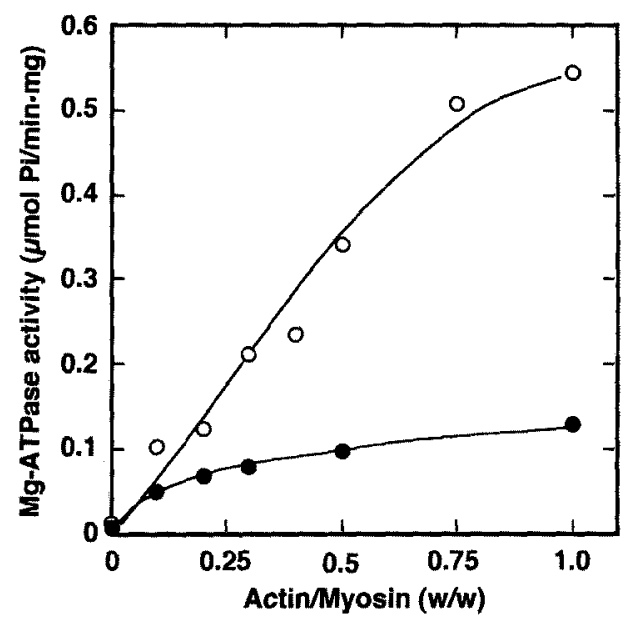

Fig. 5. Mg-ATPase activity of the walleye pollack myosin in the presence of various amounts of $\mathrm{F}$-actin.

The pollack myosin was combined with rabbit $F$-actin in various weight ratios in $1 \mathrm{M}$ sorbitol, $0.5 \mathrm{M} \mathrm{KCl}, 50 \mathrm{mM}$ Tris maleate $(\mathrm{pH} 7.0)$, and $5 \mathrm{~mm} 2$-mercaptoethanol. Mg-ATPase activity was measured at $15^{\circ} \mathrm{C}$ after preincubation for $5 \mathrm{~min}$ at the same temperature in a medium containing $50 \mathrm{mM} \mathrm{KCl}, 2 \mathrm{mM} \mathrm{MgCl}, 25 \mathrm{mM}$ Tris maleate $(\mathrm{pH} 7.0), 0.1 \mathrm{M}$ sorbitol, $1 \mathrm{mM}$ ATP, $0.05 \mathrm{mg} / \mathrm{m} / \mathrm{myosin}$ and various concentrations of rabbit F-actin. $O$, pollack myosin; $\bullet$, rabbit myosin.

Since these features seem to be characteristic to pollack myosin, we are now investigating the physiological significance of the strong actin-activation.

On the other hand, Taguchi et al. reported that walleye pollack myosin B showed heat-induced activation of $\mathrm{Mg}$ ATPase activity. ${ }^{20)}$ Therefore, we undertook a similar experiment using actomyosin reconstituted from the pollack 

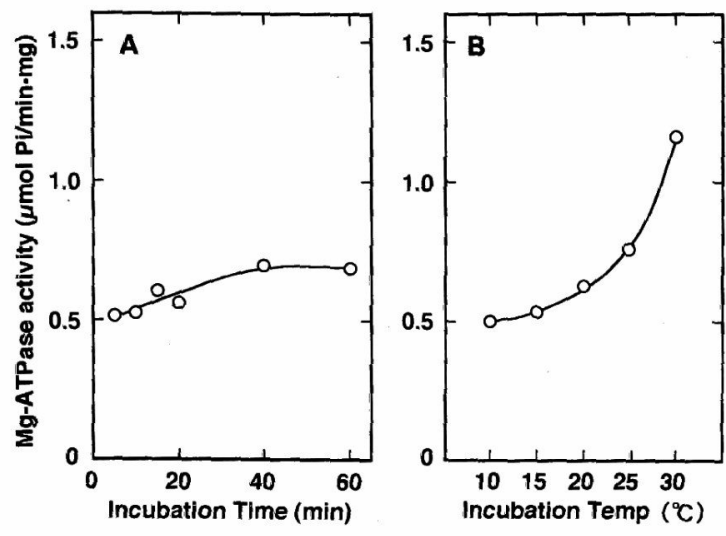

Fig. 6. Heat-induced activation of Mg-ATPase activity of acto-walleye pollack myosin.

The pollack myosin was combined with rabbit $\mathrm{F}$-actin at a weight ratio of $1: 1$ in $1 \mathrm{M}$ sorbitol, $0.5 \mathrm{M} \mathrm{KCl}, 50 \mathrm{~mm}$ Tris maleate $(\mathrm{pH} 7.0)$, and $5 \mathrm{~mm} 2$-mercaptoethanol. Then, the actomyosin was preincubated either for 0-60 min at $15^{\circ} \mathrm{C}$ in the Mg-ATPase assay medium (A), or for $5 \mathrm{~min}$ at indicated temperature on the abscissa and immediately cooled in a ice-bath (B). Then, Mg-ATPase activity was measured at $15^{\circ} \mathrm{C}$ after preincubation at the same temperature for $5 \mathrm{~min}$.

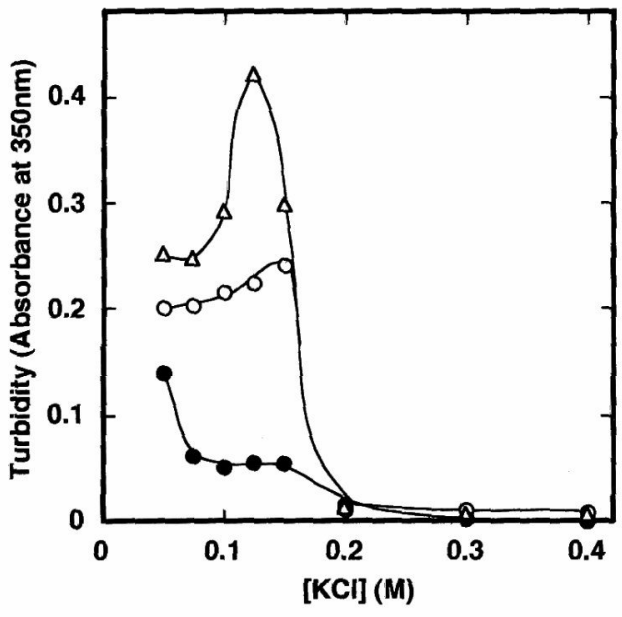

Fig. 7. Turbidity of the walleye pollack myosin as a function of $\mathrm{KCl}$ concentration.

The pollack and rabbit myosins were incubated at $8^{\circ} \mathrm{C}(0)$ and $25^{\circ} \mathrm{C}(\triangle, \bullet)$ for $5 \mathrm{~min}$ in a medium containing $25 \mathrm{~mm}$ Tris maleate (pH 7.0), $0.1 \mathrm{M}$ sorbitol, $0.2 \mathrm{mg} / \mathrm{m} / \mathrm{myosin}$, and various concentrations of $\mathrm{KCl}$. Turbidity of the myosin suspension was determined by measuring the absorbance at $350 \mathrm{~nm}$. $\bigcirc$ and $\triangle$, pollack myosin; $\bullet$, rabbit myosin.

myosin and rabbit F-actin. At first, we measured the $\mathrm{Mg}$ ATPase activity of the actomyosin at $15^{\circ} \mathrm{C}$ immediately after preincubation for various times at the same temperature in a reaction mixture. As a result, the activity was gradually increased as the preincubation time was elongated (Fig. 6A). Subsequently, the actomyosin was incubated at $10-30^{\circ} \mathrm{C}$ for $5 \mathrm{~min}$ and immediately cooled in an icewater bath, and then the Mg-ATPase activity was measured as above. As seen in Fig. 6B, the activity was sig-
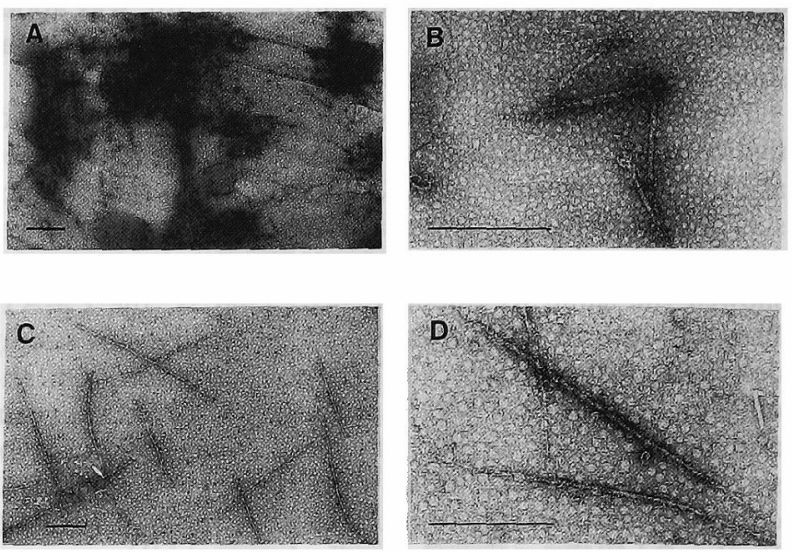

Fig. 8. Electron micrographs of thick filaments of the walleye pollack myosin.

The myosin filaments prepared were applied to a grid, negatively stained with $2 \%$ uranyl acetate, and then observed with a Hitachi $\mathrm{H}$ 7000 electron microscope as described in the text. A and B, pollack myosin; $\mathrm{C}$ and $\mathrm{D}$, rabbit myosin. Calibration bar in the photograph indicates $0.5 \mu \mathrm{m}$.

nificantly increased as the incubation temperature was raised. Thus, the heat-induced activation of the Mg-ATPase activity was also observed in the reconstituted actomyosin, irrespective of the species of actin. Therefore, such a high activation appeared to be attributable to heatinduced conformational changes of the pollack myosin.

\section{Filament Formation of Pollack Myosin}

It has been reported that some fish myosins form short thick filaments, so-called mini-filaments. ${ }^{21,22)}$ We therefore examined the filament forming ability of the pollack myosin by turbidity measurement and electron microscopic observation. As shown in Fig. 7, the pollack myosin exhibited significantly higher turbidity than rabbit myosin at $0.05-0.15 \mathrm{M} \mathrm{KCl}$. Even at $0.1-0.12 \mathrm{M} \mathrm{KCl}$ where rabbit myosin shows low turbidity and forms fairly homogeneous thick filaments (see Fig. 8), the pollack myosin showed high turbidity at $8^{\circ} \mathrm{C}$ and the maximum turbidity at $25^{\circ} \mathrm{C}$. Then, we observed the morphology of pollack myosin filaments by electron microscope (Fig. 8A-D). At a higher magnification $(\times 30,000$, Fig. $8 \mathrm{~B})$, the bipolar filaments of about $0.5 \mu \mathrm{m}$ in length were observed. Thus, the pollack myosin appeared to form mini-filaments like some other fish myosins. ${ }^{20,21)}$ Moreover, the mini-filaments were found to gather on a grid at a lower magnification ( $\times 10,000$, Fig. $8 \mathrm{~A})$.

To understand the gel forming mechanism of the walleye pollack surimi, more detailed studies are required on the properties and structure of the myosin.

\section{References}

1) N. Kato, A. Hashimoto, H. Nozaki, and K. Arai: Effect of temperature on the rate for the setting of meat pastes from Alaska pollack, white croaker and tilapia. Nippon Suisan Gakkaishi, 50, 2103-2108 (1984).

2) T. Numakura, N. Seki, I. Kimura, K. Toyoda, T. Fujita, K. Takama, and K. Arai: Cross-linking reaction of myosin in the fish 
paste during setting (suwari). Nippon Suisan Gakkaishi, 51, 15591565 (1985).

3) S. F. Noguchi: Dynamic viscoelastic changes of surimi (minced fish meat) during thermal gelation. Nippon Suisan Gakkaishi, 52, 12611270 (1986).

4) S. Nishimoto, A. Hashimoto, N. Seki, I. Kimura, K. Toyoda, T. Fujita, and K. Arai: Influencing factors on changes in myosin heavy chain and jelly strength of salted meat past from Alaska pollack during setting. Nippon Suisan Gakkaishi, 53, 2011-2020 (1987).

5) T. Numakura, R, Mizoguchi, I. Kimura, K. Toyoda, T. Fujita, N. Seki, and $\mathrm{K}$. Arai: Changes in gel forming ability and cross-linking ability of myosin heavy chain of Alaska pollack surimi denatured by heat treatment. Nippon Suisan Gakkaishi, 55, 1083-1090 (1989).

6) N. Seki, H. Uno, N. Lee, I. Kimura, K. Toyoda, T. Fujita, and K. Arai: Transglutaminase activity in Alaska pollack muscle and suri$\mathrm{mi}$, and its reaction with myosin B. Nippon Suisan Gakkaishi, 56, 125-132 (1990).

7) M. Ishioroshi, K. Samejima, and T. Yasui: Further studies on the roles of the head and tail regions of the myosin molecule in heat-induced gelation. J. Food. Sci, 47, 114-120 and 124 (1981).

8) K. Samejima, H. Yamaguchi, A. Asghar, and T. Yasui: Role of myosin heavy chains from rabbit skeletal muscle in the heat-induced gelation mechanism. Agr. Biol. Chem., 48, 2225-2232 (1984).

9) K. Samejima, K. Kuwayama, K. Yamamoto, A. Asghar, and T. Yasui: Influence of reconstituted dark and light chicken muscle myosin filaments on the morphology and strength of heat-induced gels. J. Food Sci., 54, 1158-1162 and 1168 (1989).

10) T. Akahane, S. Chihara, Y. Yoshida, T. Tsuchiya, S. Noguchi, H. Ookame, and J. J. Matsumoto: Roles of constituent proteins in gel properties of cooked meat gel. Nippon Suisan Gakkaishi, 43, 237 (1977).

11) T. C. Lanier, T. S. Lin, Y. M. Liu, and D. D. Hamann: Heat gelation properties of actomyosin and surimi prepared from Atlantic croaker. J. Food Sci., 47, 1921-1925 (1982).
12) I. Kimura, M. Takahashi, E. Nagahisa, and T. Fujita: Preparation of monomeric myosin from Alaska pollack frozen surimi. Nippon Suisan Gakkaishi, 48, 251 (1982).

13) S. V. Perry: Myosin adenosinetriphosphatase, in "Methods in Enzymology" (ed. by S. P. Colowick and N. O. Kaplan.) vol. 2, Academic Press, New York, 1955, pp. 582 -588 .

14) J. A. Spudich and S. Watt: The regulation of rabbit skeletal muscle contraction. I. Biochemical studies of the interaction of the tropomyosin-troponin complex with actin and the proteolytic fragments of myosin. J. Biol. Chem., 246, 4866-4871 (1971).

15) G. E. Youngburg and M. N. Youngburg: Phosphorus metabolism I. A system of blood phosphorus analysis. J. Lab. Clin. Med., 16, 158-166 (1930).

16) M. A. Porzio and A. M. Pearson: Improved resolution of myofibrillar proteins with sodium dodecyl sulfate-polyacrylamide gel electrophoresis. Biochim. Biophys. Acta, 490, 27-34 (1977).

17) A. G. Gornall, C. S. Bardawill, and M. N. David: Determination of serum proteins by means of the biuret reaction. J. Biol. Chem., 177, 751-766 (1949).

18) K. Nishita, T. Ojima, and S. Watanabe: Myosin from striated adductor muscle of Chlamys nipponensis akazara. J. Biochem., 86, 663-673 (1979).

19) R. Takashi, T. Murozuka, and K. Arai: Light chains of myosin from fish dorsal and rabbit skeletal muscles. Nippon Suisan Gakkaishi, 40, 1063-1069 (1974).

20) T. Taguchi, K. Kikuchi, M. Oguni, M. Tanaka, and K. Suzuki: Heat changes of myosin B Mg ${ }^{2+}$-ATPase and "setting" of fish meat paste. Nippon Suisan Gakkaishi, 44, 1363-1366 (1976).

21) M. Matsuura and K. Arai: Filament forming ability of tilapia myosin, in association with biochemical activities. Nippon Suisan Gakkaishi, 51, 1697-1704 (1985).

22) M. Matsuura, K. Konno, and K. Arai: Thick filaments of fish myosin and its actin-activated $\mathrm{Mg}$-ATPase activity. Comp. Biochem. Physiol., 90B, 803-808 (1988). 